CORRECTION

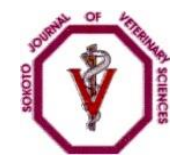

Sokoto Journal of Veterinary Sciences (P-ISSN 1595-093X: E-ISSN 2315-6201)

Saidu et al. /Sokoto Journal of Veterinary Sciences, 18(3): 181

\title{
Correction to: Comparison of electrocardiographic parameters of racing and non-racing horses in Sokoto Nigeria
}

\author{
B Saidu ${ }^{1 *}$, Al Ja'afaru ${ }^{1}$, HM Ibrahim ${ }^{1}$, A Dahiru ${ }^{1}$, AM Abdullahi ${ }^{2}$, C Onwuchekwa $^{3}$, N \\ Abdulazeez $^{1}$, NN Pilau ${ }^{4}$, A Abdulrasheed ${ }^{1} \&$ AJ Bamaiyi $^{3}$ \\ 1. Department of Physiology and Biochemistry, Faculty of Veterinary Medicine Usmanu Danfodiyo \\ University Sokoto, Nigeria \\ 2. Veterinary Teaching Hospital, Faculty of Veterinary Medicine, University of Maiduguri, Nigeria \\ 3. Department of Physiology, Faculty of Basic Medical Sciences, Usmanu Danfodiyo University Sokoto, \\ Nigeria \\ 4. Department of Medicine, Faculty of Veterinary Medicine Usmanu Danfodiyo University Sokoto, \\ Nigeria
}

*Correspondence: Tel.: +2348032982399; E-mail: dr.bashvet11@gmail.com

The initial version of the article published in Volume 18 number 1 (March, 2020) contained errors in the names of AJ Ishaq and N Abduazeez. Their correct names are: $\mathbf{A l}$ Ja'afaru and $\mathbf{N}$ Abdulazeez, respectively.

Correction to: http://dx.doi.org/10.4314/sokjvs.v18i1.5 